\title{
PATHOLOGICAL STUDY OF RETINOBLASTOMA TREATED BY RADON SEEDS AND RADIUM DISKS* ${ }^{*}$
}

BY

\author{
H. B. STALLARD
}

London

RADIATION is a type of energy which occurs in two forms:

(1) Electro-magnetic vibration. Light. Roentgen rays.

(2) Corpuscular radiation. $\alpha$ and $\beta$ rays. Neutrons.

That part of the Arndt-Schulze law which states that small doses of radiation stimulate cell proliferation is strongly disputed in the literature of radio-biology; in fact Strangeways and Hopwood (1926) found no evidence of any stimulating effect by $x$ rays on cells in tissue culture and this has also been confirmed by such an authority as Bloom (1948). The medium irradiation doses are depressive and the large doses are destructive. The effect of irradiation is governed by the specific radio-sensitivity of cells and tissues, and the factors concerned in this are the equation of several variables. The more important of these are the following:

(1) Degree of Cell Differentiation.-The more undifferentiated, immature, atypical, character of the tissues, and the ability of certain cell strains to proliferate rapidly the greater is the radio-sensitivity.

(2) State of Mitotic Activity of the Cells.-During mitosis there is increased sensitivity of both normal and pathological cells which rises in the prophase and is greatest in the equatorial-plate phase. Strangeways and Hopwood, when investigating the effect of $x$ rays on mitosis in tissue cultures, found that cells pass through a phase immediately before visible prophase during which the physiological processes of the cell are especially liable to be disturbed. The process of cell division becomes abnormal and may result in complete disruption of the cell. Indeed, during the chromosome state a larger surface of chromatin is exposed to irradiation than at other times in the life of the cell. There are waves of mitosis in normal tissues which must be taken into account.

When cell metabolism is increased in direct relation to cell growth and where the degree of swelling of the colloid is augmented radio-sensitivity is higher.

(3) Nature of the Tissues in which the Neoplasm arises.-In general, if the tissue from which the growth arises is radio-sensitive, then the neoplasm will also be radio-sensitive, and Ellinger (1941) has stated that " tumours arising in radioresistant tissue are invariably radio-refractory and are to be described as radioresistant tumours". The latter is not true in the case of retinoblastoma, for although the retina in common with other parts of the nervous system is resistant

- Received for publication November 28, 1951.

+ First part of the William McKenzie Memorial Lecture, 1951. 
to irradiation, even at doses which are several times more than that which injures blood-forming tissues, the undifferentiated atypical cells of retinoblastoma are highly radio-sensitive. So with retinoblastoma there is the unique and favourable condition of a very radio-sensitive neoplasm arising from relatively radio-resistant tissue.

(4) Blood Supply of the Neoplasm.-The richer the blood supply the more radio-sensitive is the neoplasm. The reason that smaller neoplasms are more radiosensitive than larger growths is probably due to the fact that they have a better blood supply. This is certainly true in retinoblastoma. It is evident that radiosensitivity is reduced in anoxaemia.

(5) Age.-Radio-sensitivity is greater in the young than in the old.

(6) Constitutional State.-Radio-sensitivity is reduced by cachexia, suppuration, tuberculosis, and syphilis.

(7) Previous Irradiation Treatment.-This may cause the tissues to acquire resistance to radium and $x$ rays.

\section{Material of Present Investigation}

I have studied pathologically eight eyes containing irradiated retinoblastoma. Two were completely full of the growth and were used in 1930 and 1931 to assess the effective range of a $3.5 \mathrm{mc}$. radon seed inserted interstitially and left in place for 10 days. One child had a clinical cure of retinoblastoma in the remaining eye, but unfortunately died 11 months later from a recurrence in the orbit from which the other more severely affected eye had been excised. Another child, one year after successful irradiation of three large masses of retinoblastoma around the optic disk, had an intra-ocular haemorrhage and complicated glaucoma. Three children had more than half the retina affected by the growth and a total detachment, and so were most unfavourable cases for irradiation; and there was one patient in whom three-quarters of the retina were involved and who ultimately lost the eye from intra-ocular haemorrhage and complicated cataract. Serial sections were cut, $16 \mu$ thick, and stained with Mallory's phosphotungstic acid haematoxylin, Feulgen's solution, Heidenhain's iron haematoxylin, haematoxylin and eosin, van Gieson's stain, and Hotchkiss's modification of McManus's stain.

\section{Histo-Pathological Changes}

Even though the cell nucleus is no longer regarded as the only radio-sensitive component of the cell (the cytoplasm being relatively radioinsensitive), it is still consistent with modern concepts to regard it as an important indicator of post-irradiation intra-cellular changes and as an expression of radio-sensitivity. Nevertheless, it is probable that the nuclear changes are not entirely the result of direct irradiation but may be due also to cytoplasmic changes. 
The histological features of an irradiated cell are increases in the size of the nucleus and of the cytoplasm. In the nucleus the chromatin is clumped, broken up into minute spherules, and distributed irregularly around the periphery on the nuclear membrane (pyknosis). In some cases the chromatin granules project from the periphery of the cell as small excrescences. Lobulation is sometimes evident, the nucleoli assume a signet-ring shape, liquefaction occurs with vacuole formation, and disintegration of the nucleus (karyorrhexis) is followed by its fragments entering the cytoplasm. The cell outline becomes less distinct, vacuolation occurs and the size of the cytoplasm increases. Fig. 1 shows these changes in retinoblastoma cells 10 days after interstitial irradiation with a 3.5 mc. radon seed.

Mitosis.-Atypical mitosis is shown by clumping and lagging of the chromosomes, and by multipolar asters. Mitosis does not become complete and may remain at the equatorial-plate stage. In the case of those cells which had already begun to divide when irradiation struck them, the process was completed but the daughter cells developed into giant cells. Ultimately denaturation of the proteins and their precipitation produces an irreversible change characteristic of irradiation coagulation necrosis in the cell which is radio-sensitive. In the case of retinoblastoma it is most likely that this change accounts for the altered ophthalmoscopic appearance of the neoplasm 2 or 3 days after irradiation, for its

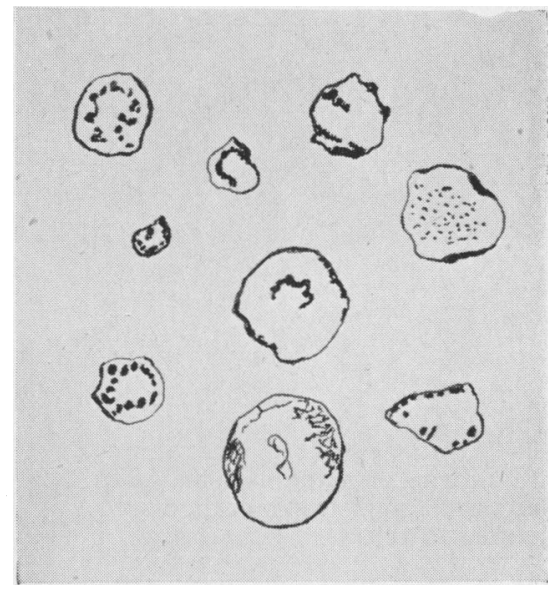

FIG. 1.-Retinoblastoma cells 10 days after being within the effective zone of gamma emanations from a 3.5 millicurie radon seed inserted interstitially into the neoplasm. Pyknosis, chromatin excrescences from the cell membrane, lobulation, and karyorrhexis are shown. (From Brit. J. Ophthal., Monograph Suppl. No. 6, Gifford Edmonds Prize Essay, 1932.) greyish-white, granular appearance changes to a dense white flocculent mass, from which flakes like curdled milk separate off.

Glücksman and Tansley (1936) found in the immature eyes of newborn rats that quite small exposures of radium cause a complete disappearance of cell division for about 6 hours, mitosis then reappears, but many of the dividing cells are markedly abnormal and the recovery is accompanied by a widespread cell degeneration in the outer part of the retina which is still undifferentiated at the time of exposure. The amount of degeneration after irradiation is proportional to the amount of cell division in the exposed tissue.

Vascular Changes.-It is evident from both ophthalmoscopic and microscopic examinations that the ultimate fate of irradiated blood vessels is attenuation with the disappearance of part or all of the vascular tunics. 


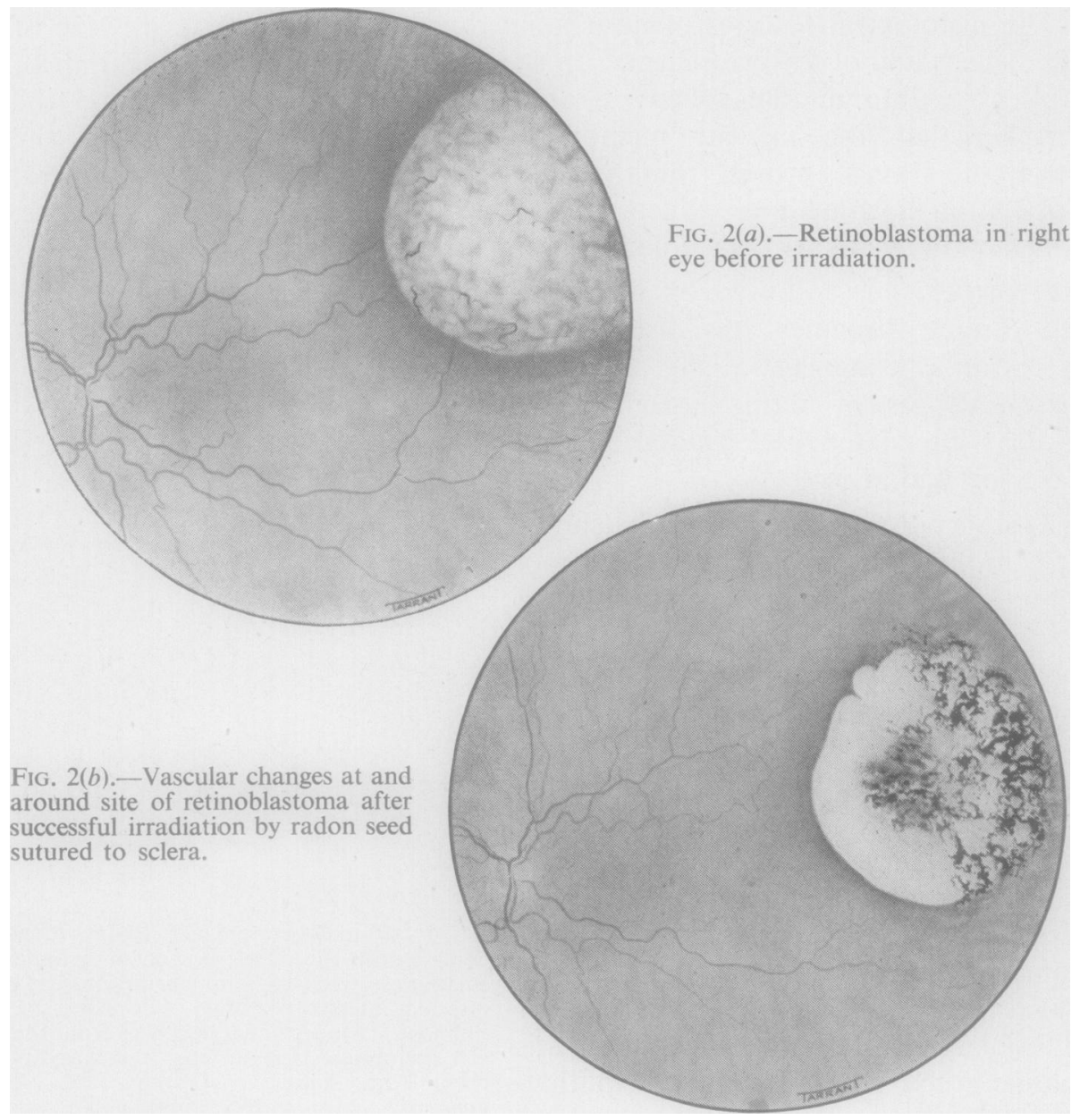

Figs $2(a)$ and $2(b)$ illustrate these changes on the nasal side where a retinoblastoma was successfully treated by suturing a radon seed to the sclera.

Microscopic examination reveals a deep brilliant pink staining of the collagen of the tunica adventitia which, in cases examined one month after radium or $x$-ray treatment, is a purple pink. Individual collagen fibres become fewer and thicker and some merge together. Most of the collagen fibres separate and project into the surrounding tissues at angles; they are wavy and some become detached. One week after irradiation these fibres become granular and disappear. In sections examined 4 to 5 months after irradiation there is no adventitia.

In the tunica media the muscle fibres become swollen and the nuclei enlarge; degeneration occurs late in some cells after high irradiation doses and they ultimately disappear. Nevertheless, muscle and elastic membrane are considered to be radio-resistant. 
The endothelial cells of the tunica intima become swollen and may obliterate the lumen of the vessels only after very high irradiation doses.

One to 2 weeks after irradiation there is a decrease in the total number of blood vessels; some are distended with blood, and others are collapsed and invisible. Indeed, in some only the naked elastic membrane remains without endothelium to line the lumen.

The varicose appearance and irregularities in calibre of some smaller vessels may be due to compression by changes in the surrounding connective tissue as well as to the irradiation changes in the vessel wall.

The admirable work of Ballantyne (1941) on the vascular changes which follow irradiation of an eye with haemangiogliomatosis retinae showed degeneration and swelling of the collagenous elements of the outer coats of the blood vessels with an abundant proliferation of elastic fibres. In the pathologically distended vessels, the tunica intima was greatly thickened and became hyaline. Such vessels showed thickening of their walls, feeble staining with eosin, and a reduced number of nuclei. In a few instances the layer of subendothelial tissue was thin. Pathologically distended vessels were more radio-sensitive than normal vessels. In the capillaries, irradiation is said to paralyse the cells of Rouget, to increase their sensitivity to dilator stimuli, and to lessen it for constrictor impulses.

These vascular changes play an important part in the disappearance of the neoplasm. Incidentally, they are also responsible for such late complications as intra-ocular haemorrhage, irradiation cataract, and the slow healing of incisions in the conjunctiva and extra-ocular muscles when the radium has been placed unavoidably near these structures.

Nerve Tissue Changes.-Desjardins (1931) found that the nervous parts of the eye are not readily damaged by $x$ rays, and Lyman, Kupalov, and Scholz (1933, quoted by Bloom, 1948), after reviewing the German and Russian literature on experimental irradiation of adult animals' eyes, stated that little or no direct change was seen in the nerve cells or fibres of the retina.

Changes in the Neoplasm.-Fig. 3 shows part of the retina which before

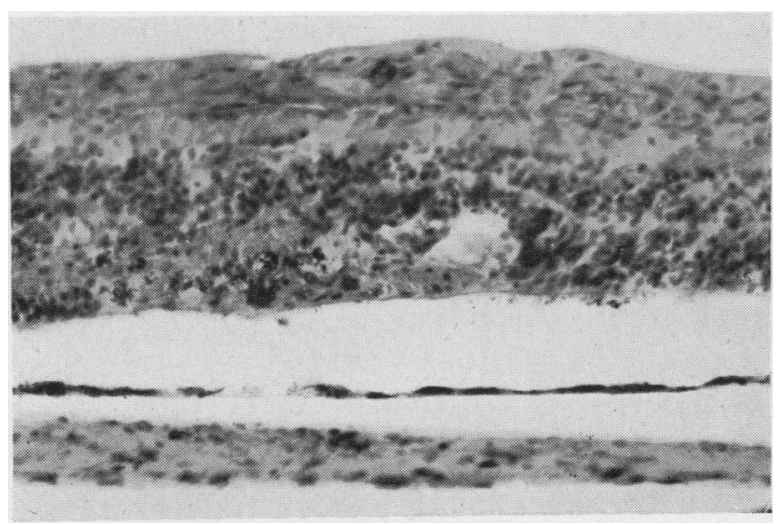

FIG. 3.-Photomicrograph of irradiated retina and choroid at site of retinoblastoma. There are no retinoblastoma cells. The vascularity of the atrophic retina and choroid is much reduced. The layer of rods and cones has disappeared and the other layers of the retina are disorganized. Pigment deposits are present in the outer nuclear and molecular layers. 
irradiation was involved in the neoplasm. In this degenerate, disorganized, atrophic area there are no retinoblastoma cells, the neoplasm has completely disappeared. The reduced vascularity of both retina and choroid is obvious.

In some cases traces of neoplastic cells persist in compressed columns and clumps surrounded by fibrous tissue, and in others there are pale-centred islands of degenerate, necrotic, and distorted cells, which stain a mauvish-pink colour with haematoxylin and eosin (Fig. 4). The central vessel in every island is absent, the cell and nuclear membranes are very faint, and chromatin

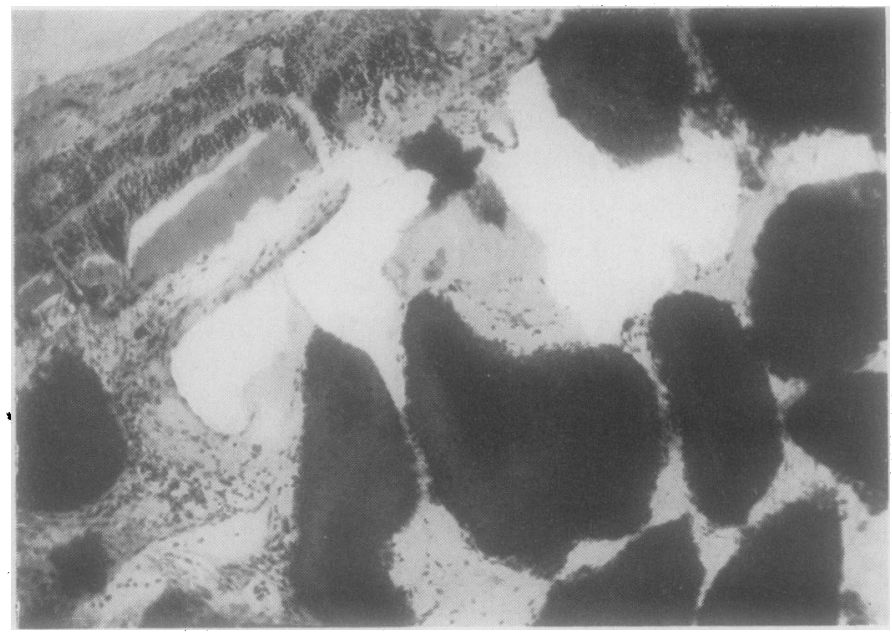

FIG. 4.-Photomicrograph of irradiated islands of retinoblastoma cells which stain a mauvish-pink with haematoxylin and eosin. The central vessel of each island is absent, the cell and nuclear membranes are very faint, and chromatin fragments stain darkly. Fibrosis is evident around some of the islands.

fragments stain darkly with the basic dyes. Around such islands appear attempts at fibrosis. In one instance there were islands of retinoblastoma cells with the nucleus staining well and histologically not necrotic which remained apparently inactive until the child died from recurrences which arose in the orbit of the excised eye

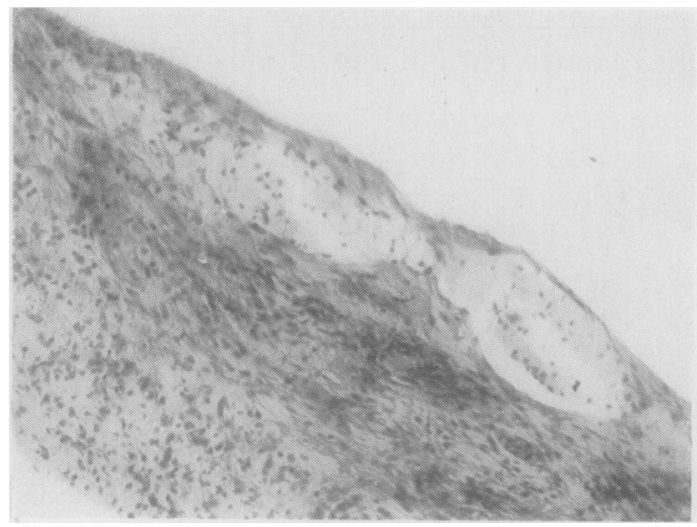

Fig. 5.-Photomicrograph of clumps of swollen 'ghost' cells in nerve fibre layer. nearly a year later. A similar case in which clumps of retinoblastoma cells remained thus for 8 years without proliferation has also been reported.

Calcification occurs in some islands after degenerative changes. Fibrosis around groups of retinoblastoma cells may be the sequel to cellular degeneration and is not specific to irradiation.

The swollen 'ghost' cells occur in the nerve fibre layer (Fig. 5), on the internal 
Fig. 6.-Photomicrograph of swollen 'ghost' cells on internal limiting membrane.

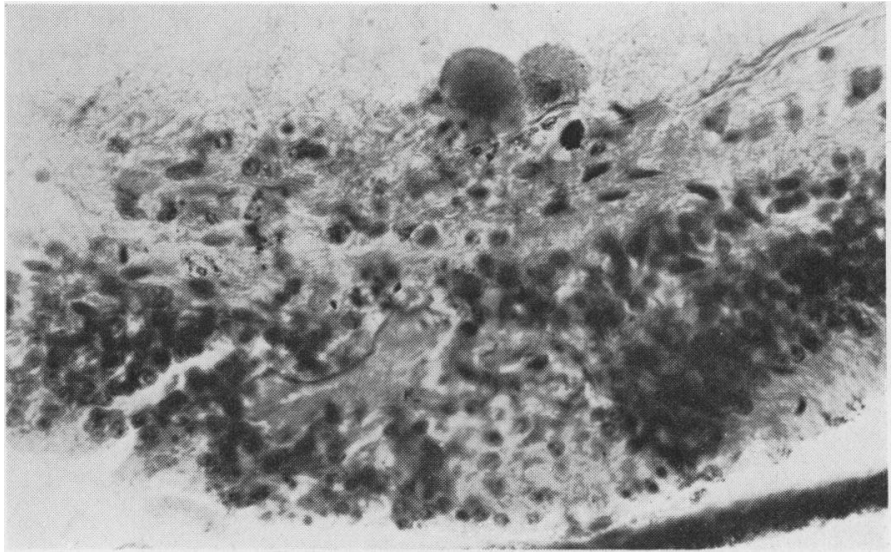

limiting membrane (Fig. 6), and in the space between the rods and cones and retinal pigment epithelium.

At and around the site of irradiation there occurs oedema of the retina (Fig. 7) which may extend 4 or $5 \mathrm{~mm}$. beyond the periphery of the neoplasm, and in specimens examined up to a year after radium treatment cystic spaces appear in the outer nuclear layer (Fig. 8). The periphery of the zone of

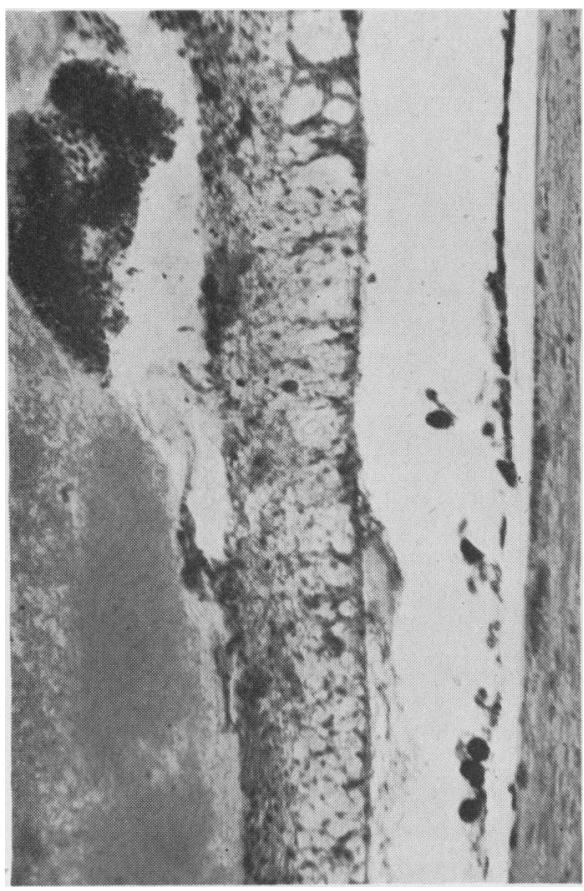

Fig. 7.-Photomicrograph showing oedema of retina at and around irradiated site.

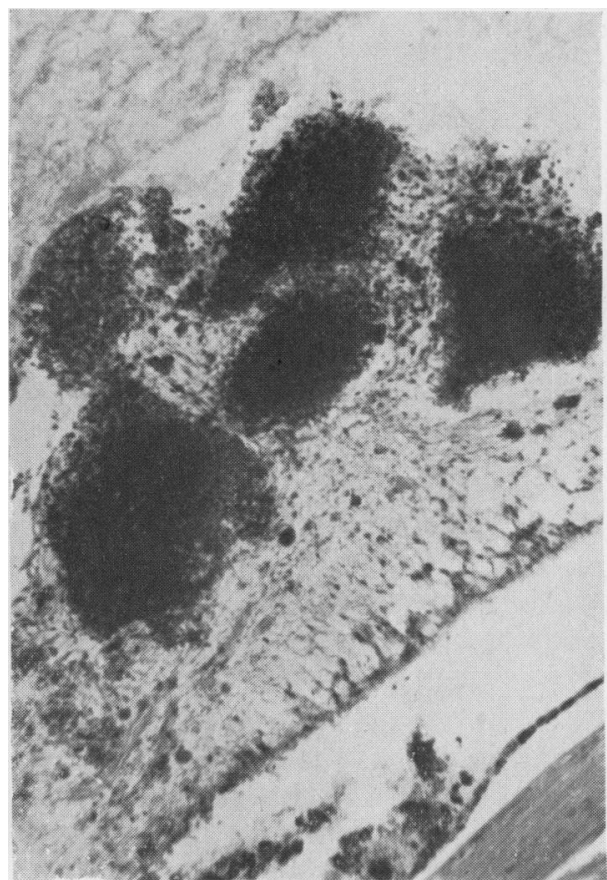

Fig. 8.-Photomicrograph showing cystic spaces in outer nuclear layer one year after irradiation. 
intense irradiation, where the radon seed or disk has been applied, shows a crenated fringe of coarse broken pigment (Fig. $2 b$ ) which in sections is represented by spherical clumps of retinal pigment epithelial cells, and the fine pigment dusting of the retina peripheral to the characteristic irradiation scar is shown by little irregular-shaped deposits of dark and honey-coloured pigment in the outer and inner molecular layers and in the ganglion cell layer of the atrophic retina (Fig. 9).

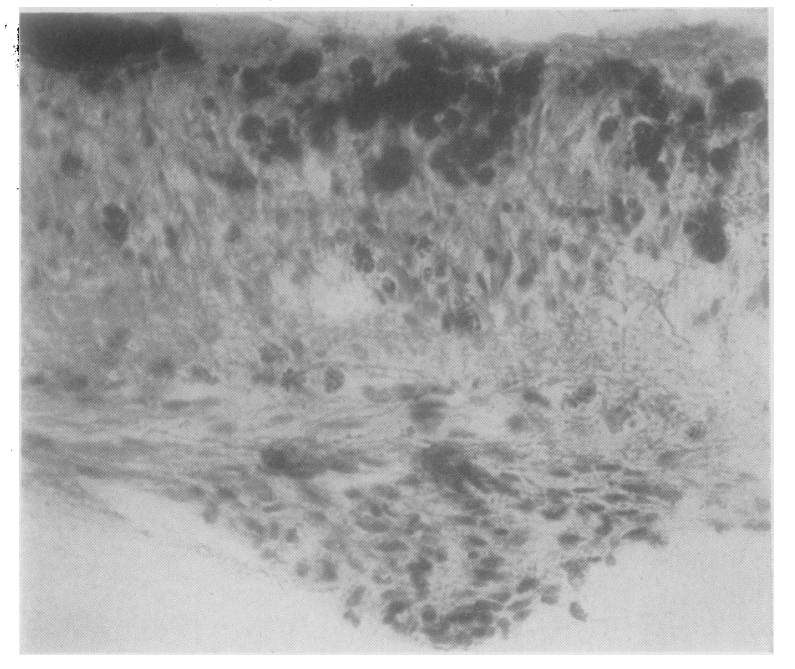

FIG. 9. - Photomicrograph showing irregular-shaped deposits of pigment in outer and inner molecular layers and in ganglion cell layer. There is also a fibrous nodule in the nerve fibre layer.

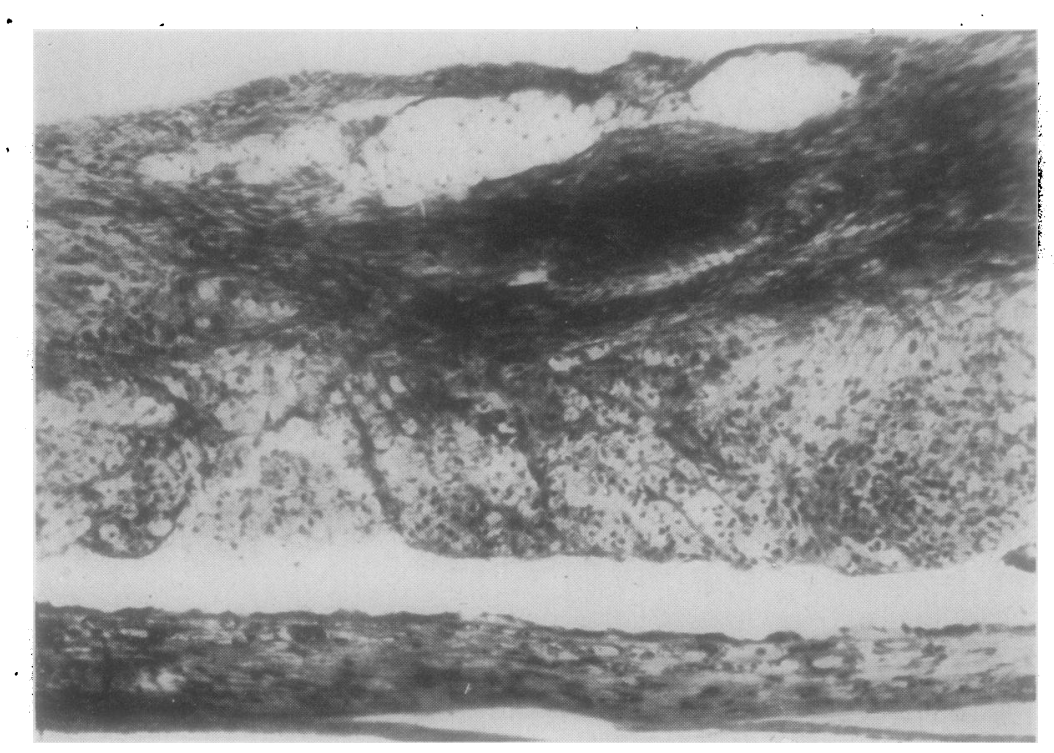
FıG. 10.-Photomicrograph showing fibrosis in degenerative nerve fibre and
ganglion cell layers. 
Many of the blood vessels disappear, and. the larger vessels become attenuated, a feature evident on ophthalmoscopic examination. Some of the vessels are thickened, the nuclei in the structures which form the vascular tunics stain faintly, and hyaline changes are present.

The ganglion cell layer is degenerate and much of it is replaced by spindle cells, presumably young fibrous tissue, which at some sites projects forwards as a small nodule (Figs 9 and 10).

In the outer nuclear and molecular layers there are in some specimens irregular-shaped deposits of homogeneous exudate and hyaline material, which stain pink with eosin. The supporting fibres of Müller are distorted at the edge of the neoplasm.

The rods and cones are destroyed and granular pigmented debris is present between the external limiting membrane and Bruch's membrane. Retinal haemorrhages occur particularly in the ganglion cell and inner molecular layers (Fig. 11).

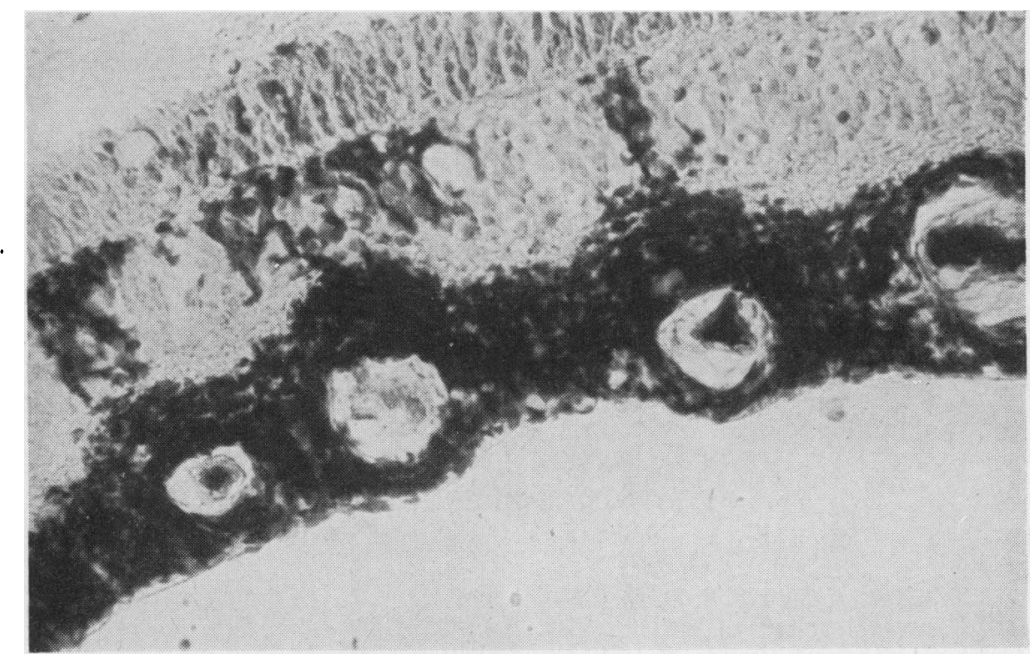

FIG. 11.-Photomicrograph showing, retinal haemorrhages in ganglion cell and inner molecular layers.

The choroid at and around the site of irradiation becomes thin and atrophic, its vascularity is much reduced, and the chorio-capillaris becomes obliterated. Infiltration of the choroid by retinoblastoma cells is regarded by radiotherapists as a bad prognostic sign. Fig. 12 (overleaf) shows irradiation cataract with so-called 'bladder cells' at the equator and in the posterior part of the cortex. In one case the epithelium of the lens capsule completely surrounded it.

It is possible that the destruction of a large mass of retinoblastoma occupying more than half the eye may have produced a toxin which has ultimately caused an endophthalmitis in one case treated by radon seeds, and in two treated by deep $x$ rays. Iridocyclitis and complicated glaucoma 


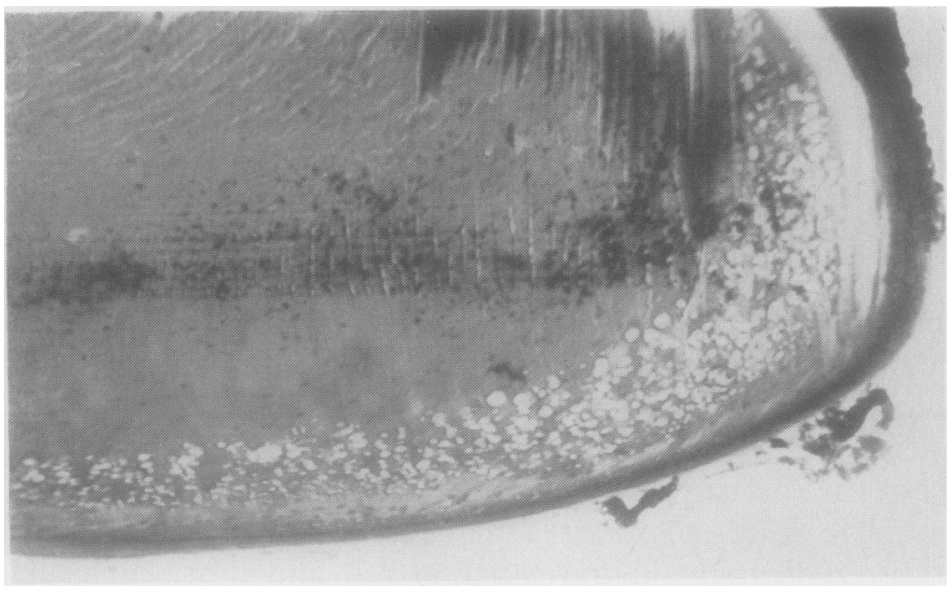

FIG. 12.-Photomicrograph of irradiation cataract showing 'bladder-cells' at equator and in posterior part of cortex.

are sequels which are rarer after treatment by radon seeds and radium disks than after deep $x$ rays.

I acknowledge with gratitude the work done by the Pathological Department (Dr. Norman Ashton) and the Medical Illustration Department (Dr. Peter Hansell) of the Institute of Ophthalmology in preparing the serial sections and in taking the photographs.

I thank the William McKenzie Memorial Committee for their kind permission to publish this part of the lecture.

\section{REFERENCES}

Ballantyne, A. J. (1941). Proc. roy. Soc. Med., 35, 345.

BLOOM, W., ed. (1948). "Histopathology of Irradiation"; McGraw-Hill Book Co., New York. Desjardins, A. U. (1931). Amer. J. Roentgenol., 26, 639 and 787.

Ellinger, F. (1941). "The Biologic Fundamentals of Radiation Therapy". Elsevier, New York. GlücksmanN, A., and TANSLEY, K. (1936). British Journal of Ophthalmology, $20,497$.

Lyman, R. S., Kupalov, P. S., and Scholz, W. (1933). Arch. Neurol. Psychiat., Chicago, $29,56$.

Strangeways, T. S. P., and Hopwood, F. L. (1926). Proc. roy. Soc. B, 100, 283.

\section{ADDITIONAL BIBLIOGRAPHY}

Ballantyne, A. J., Michaelson, I. C., and Heggie, J. F. (1938). Trans. ophthal. Soc. U.K., 58, 255.

Flexner, S. (1891). Johns Hopk. Hosp. Bull., 2, 115.

Goldstein, I., and Wexler, D. (1931). Arch. Ophthal., Chicago, 5, 591.

GlüCKSmanN, A., and Wilson, C. W. (1945). Brit. J. Radiol., 18, 158.

MARTIN, P. (1933). Trans. ophthal. Soc. U.K., 53, 246.

MOORE, R. F. (1933). Proc. roy. Soc. Med., 26, 1036. (1933). Trans. ophthal. Soc. U.K., 53, 215. (1935). Ibid., 55, 3.

Stallard, H. B., and Milner, J. G. (1931). British Journal of Ophthalmology, 15, 673.

Stallard, H. B., and Milner, J. G. (1931). British Journ
Reese, A. B. (1951). "Tumors of the Eye". Cassell, London.

SPEAR, F. G. (1935). Brit. J. Radiol., 8, 68 and 280.

Stallard, H. B. (1933). “Radiant Energy". British Journal of Ophthalmology, Monograph Supplement No. 6 (Gifford Edmonds Prize Essay, 1932). (1933). Trans. ophthal. Soc. U.K., 53, 224. (1936). Proc. roy. Soc. Med., 29, 963. (1936). Brit. med. J., 2, 962.

(1938). British Journal of Ophthalmology, 22, 604. (1948). Ibid., 32, 618.

TANSLEY, K. (1933). Ibid., 17, 321.

Spear, F. G., and GlückSmann, A. (1937). Ibid., 21, 273.

Tribondeau, L., and Belley, G. (1907). Arch. Elect. méd., 15, 907. (1907). C.R. Soc. Biol. (Paris), 63, 128. and RéCAMIER (1905). Ihid., 58, 1031. 